\title{
Diálogo con Sebastián Errázuriz
}

\author{
por \\ Sofía Asunción Claro \\ Arpista, Copenhague, Dinamarca \\ asuncion@graugaard-musik.dk
}

El 18 de mayo de 2005 los soldados del Regimiento Reforzado de Los Angeles, ciudad de la VII Región, durante el descenso desde el refugio cordillerano de Los Barros, ubicado en los faldeos del volcán Antuco, fueron sorprendidos por una tormenta de viento blanco. Durante esta marcha murieron 44 reclutas y un sargento, transformándose este hecho en la peor tragedia del Ejército de Chile en tiempos de paz.

Esta catástrofe inspiró la ópera en dos actos Viento blanco, con música del compositor chileno Sebastián Errázuriz y libreto de Felipe Ossandón, Rodrigo Ossandón y del propio Sebastián Errázuriz. La función de estreno de la ópera y su repetición se realizaron en el Teatro Municipal de Santiago, los días 5 y 6 de marzo de 2008. El director musical de la obra fue José Luis Domínguez y la regiey diseño integral estuvo a cargo de Rodrigo Claro. El elenco que cantó en ambas funciones fue el siguiente: Homero Pérez-Miranda (Sargento), Juan Pablo Dupré (Recluta 1), Sergio Gallardo (Recluta 2), Mauricio Miranda (Recluta 3), Pedro Espinoza (Mayor), Daniela Ezquerra (Enamorada), Pablo Oyanedel (Comandante en jefe), Paula Arancibia (Periodista 1), Maribel Villarroel (Periodista 2), Carmen Luisa Letelier (Madre de Recluta 2), David Gáez (Padre de Recluta 2), Pablo Ortiz (Padre de Recluta 3), José Miguel Valdés (Hermano de Recluta 3) y Paula Arancibia (preparación vocal del Hermano de Recluta 3). Además, en la presentación de Viento blanco tomaron parte la Orquesta Filarmónica de Santiago, el Coro del Teatro Municipal, que dirige Jorge Klastornick y el Coro Crecer Cantando, conducido por Víctor Alarcón.

La creación de Vien to blan co se financió con aportes del Fondo de Fomento de la Música Nacional 2006, para ser estrenada en marzo del 2008, como cierre de la Temporada de celebración de los 150 años del Teatro Municipal de Santiago.

Estando de paso por Santiago de Chile, me llevé la enorme y grata sorpresa de coincidir con el estreno de la ópera Viento blanco de Sebastián Errázuriz. Antes había estado presente en el estreno de la ópera Fulgor y mu erte de Joaquín M urieta, de Sergio Ortega, realizado en el Teatro Municipal de Santiago el 14 de diciembre de 1998 y desde entonces no se estrenaba una ópera de un compositor nacio-

Revista M usical Chilena, Año LXII, Julio-Diciembre, 2008, Nº 210, pp. 46-57 
nal. ¿Responde esta iniciativa a una nueva actitud del Teatro y su dirección, destinada a promover nuestra propia música? ¿Es un caso aislado o constituye una nueva política de apertura hacia modos actuales de creación?

Cuando asistí a la premiere de Viento blanco, también me causó sorpresa el constatar que el libreto no estaba enfocado con un planteamiento crítico. No hay ningún cuestionamiento sobre los hechos que llevaron a estos sucesos; ni siquiera se insinúa la extraordinaria estupidez humana y la falta de crítica de nuestras sociedades frente al problema del autoritarismo. Tampoco se señalan las consecuencias de ello ante una tragedia de tal magnitud.

Todas estas incógnitas me llevaron a sostener el siguiente diálogo con Sebastián Errázuriz:

SAC: Me pregunto por qué en el planteamiento de la historia o sea en el libreto -que me imagino es lo primero que se ha hecho-no se cuestiona el origen de este drama. El papel del artista no solamente es mostrar los conflictos románticamente y decir ¡qué deplorable! Eso no basta. Hoy, más que nunca, su papel es señalar el origen de las contradicciones y sus consecuencias, comprometerse con el dolor desde una actitud objetiva de observador, ayudar a expandir la comprensión de la maraña psicosocial en que se está inmerso, ir a la verdad, al "origen de la tragedia” -en términos de Nietzsche- para conseguir una dimensión y un marco profundo, en el que la temática tendrá una proyección impactante, que servirá para educar, mostrar -e indirectamente- agilizar las vetustas estructuras y códigos sociales, satisfacer el intelecto a la vez de la experiencia artística misma, y abrir, de ese modo, espacios que indiquen caminos para hablar desde el momento histórico presente. La ruptura en el arte no puede ser menor que antes.

SE: La primera lectura que se hace de la tragedia de Antuco es "otra vez los milicos causando estragos en el país”, de lo cual se deduciría un libreto de corte político. Sin embargo, fue a través de este lamentable suceso que -desde el mundo civilnos dimos cuenta que detrás de un uniforme hay una persona que siente, llora, se conmueve. La imagen del Comandante en Jefe del Ejército llorando porque "se nos acaban de morir 45 hijos", me impactó profundamente. Desde esa óptica se escribe el libreto de Viento blanco, adoptando una mirada sociológica. Las preguntas fundamentales son: ¿Por qué llega a pasar algo tan terrible? ¿Cómo es que nadie advirtió que la marcha no debía realizarse, siendo tan evidentes las malas condiciones climáticas? Al hacernos esas preguntas llegamos a la convicción de que aquí no hay buenos ni malos. Estamos ante una estructura organizacional jerárquica, en la que el individuo se limita a recibir y aplicar al pie de la letra una orden, sin cuestionamientos. Y este sistema se traspasa descarnadamente al mundo civil chileno. ¿Cuántas veces recibimos una orden absurda que acatamos sabiendo que puede conducir a una catástrofe?

SAC: Este suceso no tiene nada que ver con "otra vez los milicos causando estragos en el país" si tú te refieres a la dictadura, porque aquí no hay nada de corte político. Se trata de un drama humano que sucede en la naturaleza. 
SE: Sí, estoy de acuerdo, pero no pocas personas hicieron esa lectura en la que el militar es siempre el culpable y victimario, lo que tiene una explicación muy razonable en la herencia de la dictadura, la que también se ha transformado casi en una muletilla generacional, en la que la causa de cualquier desgracia es, a la larga, culpa de Pinochet. Con varias personas discutí el tema y me fui dando cuenta que las personas mayoritariamente (algunas por vez primera) sintieron que detrás del uniforme puede haber un ser sensible que ha sido golpeado por una tragedia. Por algunos días fueron los militares quienes tuvieron «desaparecidos»y ahí también se produjo una catarsis de entendimiento entre civiles y militares, compartiendo el sentimiento de no saber dónde están tus seres queridos.

SAC: Sebastián, me encantó tu música, así es que quiero saber todo sobre este proyecto que llegó a tan buen término. Dime cuándo, cómo y por qué nació en ti la idea de escribir una ópera con este tema.

SE: Desde el 2003 estuve buscando un argumento que me motivara a escribir una ópera. Busqué en la literatura y en la dramaturgia chilena contemporánea... y nada me convencía del todo. Quería que mi primera ópera cumpliera con los elementos centrales del género y para eso necesitaba un material trágico, emotivo y con una carga visual impactante para ser puesta en escena. Cuando el 2005 ocurre la tragedia de Antuco, estuve muy conmovido siguiendo la noticia, pero no hice de inmediato la relación como para sacar de ahí el tema para empezar a escribir. Fue recién el 2006 que surgió la idea de abordar el asunto de Antuco. Era un tema que reunía todos los requisitos, y me permitía, además, hacer un homenaje a los 45 compatriotas que murieron en aquella absurda marcha. Escribí una sinopsis que daba cuenta de la estructura dramática de la obra y un esbozo de los personajes principales. Luego contacté a Felipe y Rodrigo Ossandón para que se hicieran cargo de transformar aquel borrador en un libreto. La parte visual de la puesta en escena la encargué al regisseur Rodrigo Claro. Conformado este equipo creativo multidisciplinario enviamos el proyecto al Fondo de Fomento de la Música Nacional (FONDART), el que, luego de una enérgica apelación, nos dio su aporte.

Paralelamente, sostuve conversaciones con directores y directivos del Teatro Municipal manifestándoles mis inquietudes como compositor. Afortunadamente se habían programado antes un par de obras mías en ese escenario con un muy buen resultado, lo que me ayudó en tener credibilidad frente a un medio tan exigente.

SAC: ¿En tus composiciones anteriores has usado mucho la voz humana?

SE: Había escrito un par de obras para soprano y grupo de cámara con textos del poeta chileno Diego Maquieira, y, como estudiante, una pieza breve para coro, que fue parte de mi examen de título. Pero sin duda lo más relevante en mi manejo de la voz es el hecho de haberme enamorado de una maravillosa soprano y directora de coro. Cuando vives con una cantante se hace más fácil entender cómo se mueven las voces, qué puedes hacer con ellas y qué no. De hecho, para conquistarla, le escribí una obra con textos de la poetisa argentina Alfonsina Storni 
(la misma que inspiró la canción Alfonsina y el mar de Ariel Ramírez). La estrenó con la Orquesta Mayor, que dirige el maestro Luis José Recart. Pero además de mi historia sentimental, mucho, mucho estudio. Revisar obras para voces y escuchar y ver todas las óperas posibles. Conversar con cantantes y asistir a sus ensayos hace posible conocer la materia prima con la que puedes contar.

SAC: Que bueno lo que me cuentas de tu amor, o sea que se repite lo de "cherchez la femme" ... Dime, ¿cómo expresas en la ópera el drama de las familias frente a la autoridad?

SE: Para ello se pueden citar, como ejemplo, los compases 255 a 266 de la partitura, correspondientes al Cuadro cuarto de la ópera. Allí se ven las reacciones desesperadas de los familiares ante las vagas explicaciones del Comandante en jefe del Ejército (ver ejemplo $\mathrm{N}^{\circ} 1$ ).

SAC: Ahora, explícame, ¿cómo expresas la verticalidad del mando?

SE: Esto se observa en el Cuadro tercero (compases 620 a 663), en el dúo final entre el Mayor y el Sargento. En ese momento se alcanza el clímax del tema de la verticalidad del mando (ver ejemplo $\mathrm{N}^{\circ}$ 2). Más adelante, en el Epílogo de Viento blanco, se desarrolla ese tema instrumentalmente.

SAC: Me gustaría que me dijeras cuántas obras has compuesto y de qué especie: música de cámara, obras sinfónicas, ...

SE: Mi catálogo contempla más de 30 obras. Música sinfónica, música para orquesta de cuerdas, cuartetos, música de cámara, canciones, composiciones de jazz, bandas sonoras de cine, y música para teatro.

SAC: ¿Han sido todas estrenadas? Y si no todas... ¿por qué no ha sido así?

SE: Afortunadamente tengo siempre una lista de encargos, lo que me permite entregar una obra para que sea estrenada muy luego. Son muy pocas mis obras que han quedado sin estrenar. Me ha ocurrido que envío una obra nueva a un concurso y no pasa nada, pero luego de un tiempo se estrena con buena acogida por parte de los músicos y del público. Esto muestra que los concursos de composición no deben ser la única aspiración del compositor.

SAC: ¿Con qué dificultades se encuentra un compositor aquí, en Chile, en relación con su profesión?

SE: Con la escasa programación de obras nuevas; con los casi inexistentes encargos pagados; con que somos los artistas los que subvencionamos el arte; con que no hay editores de música; con que aún no está aceptado socialmente el hecho de que se puede vivir del arte; con que el medio está plagado de egocéntricos "chantas" que traban el avance de las cosas, etc.

SAC: Lo que señalas demuestra que estamos muy lejos de ver la importancia que tiene la cultura artística en una sociedad. ¿Cómo puede ser que se le encargue una obra a un profesional -porque tú eres un profesional, como un ingeniero 
Ejemplo $\mathrm{N}^{\circ}$ 1. Viento blanco [O-33], cc. 255-266.

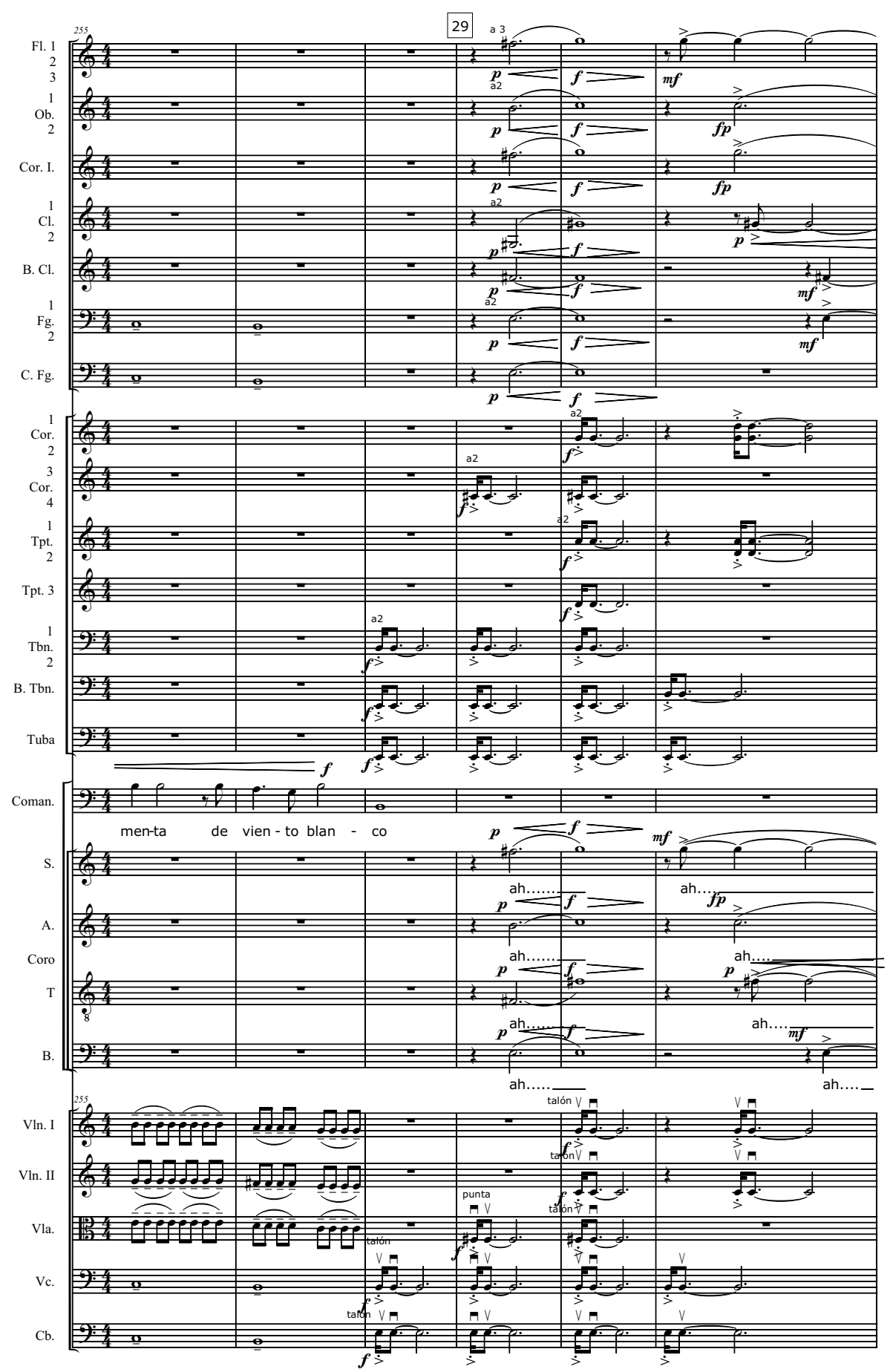




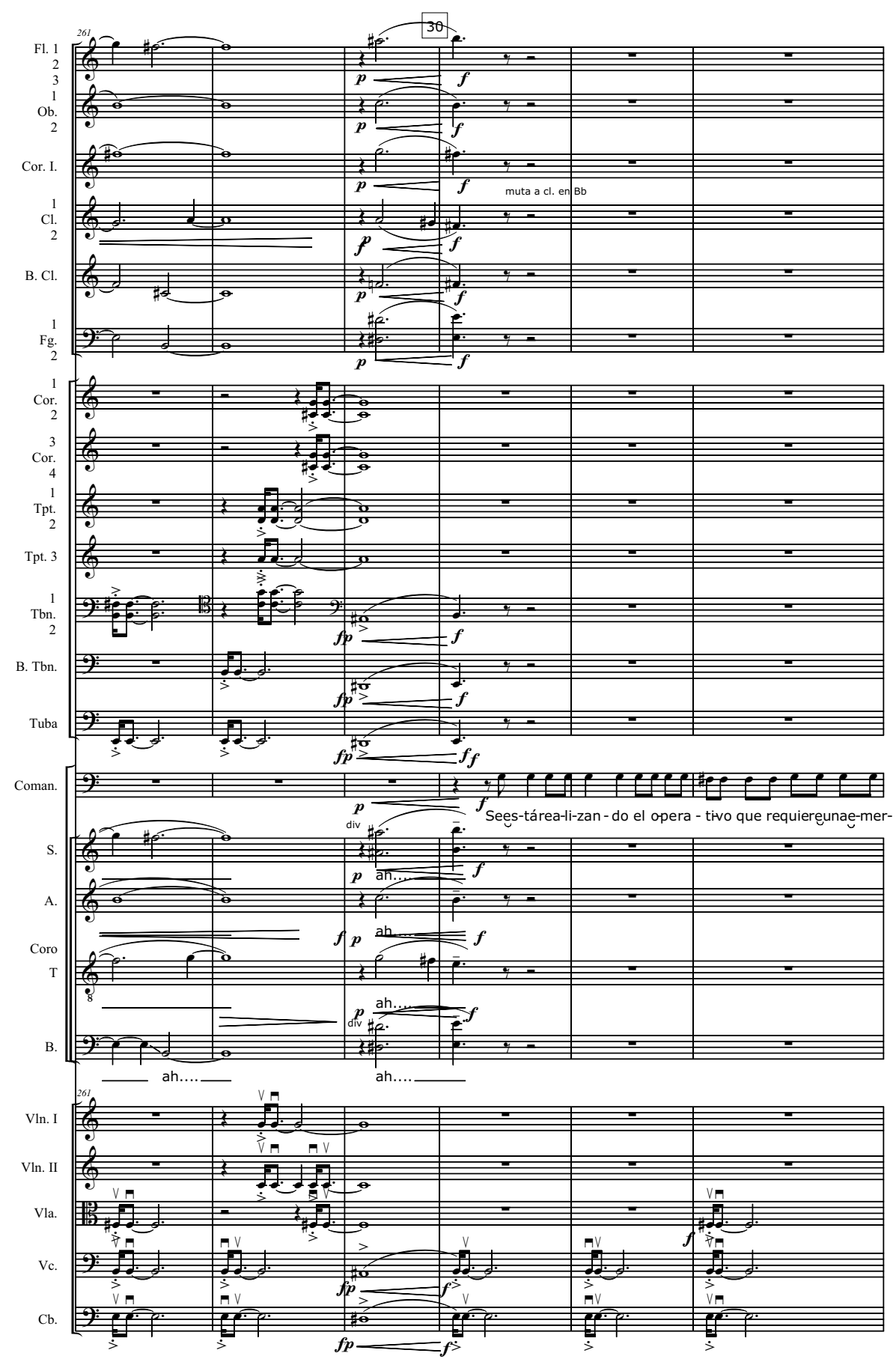


Ejemplo $\mathrm{N}^{\circ}$ 2. Viento blanco [O-33], cc.620-672
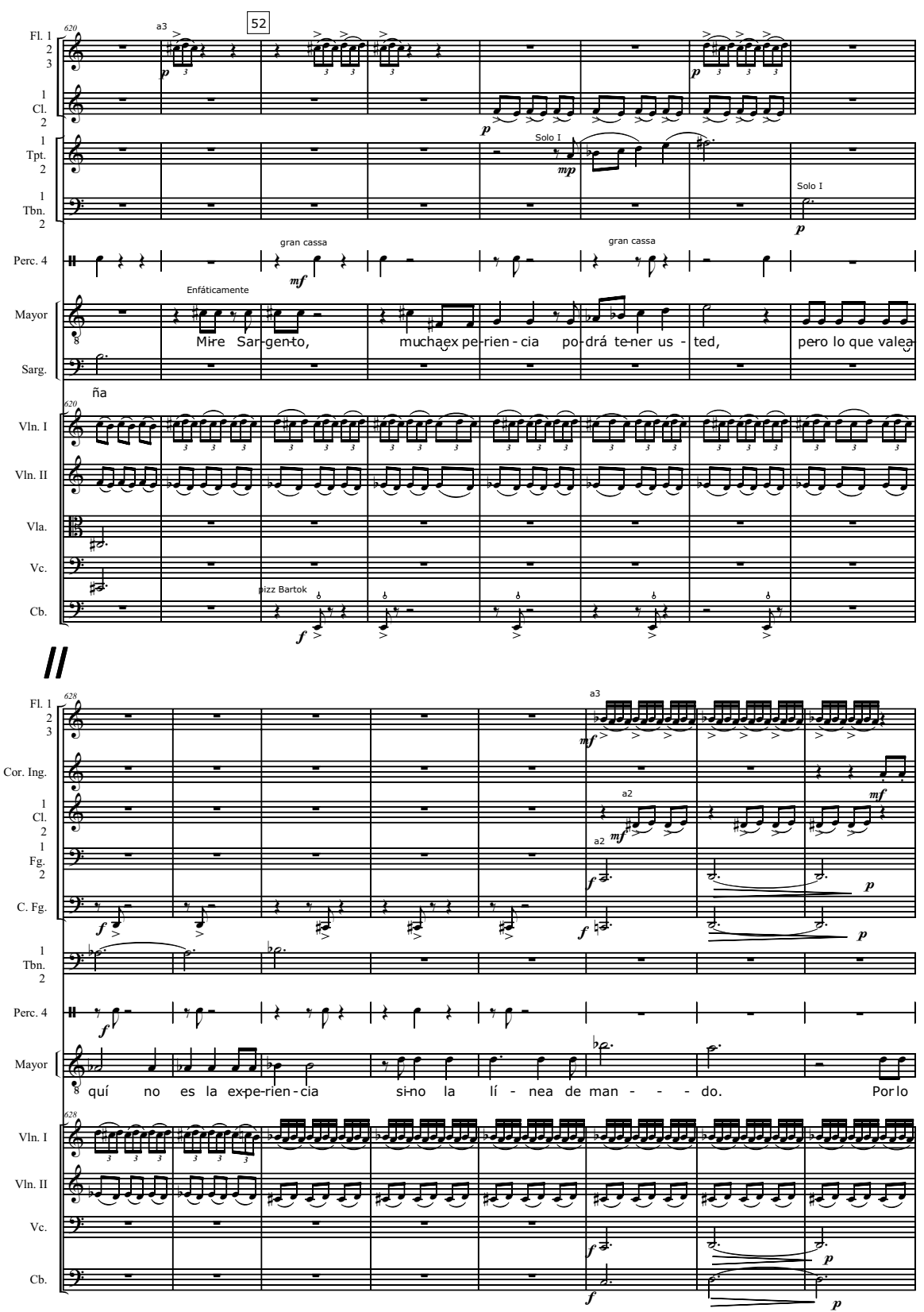


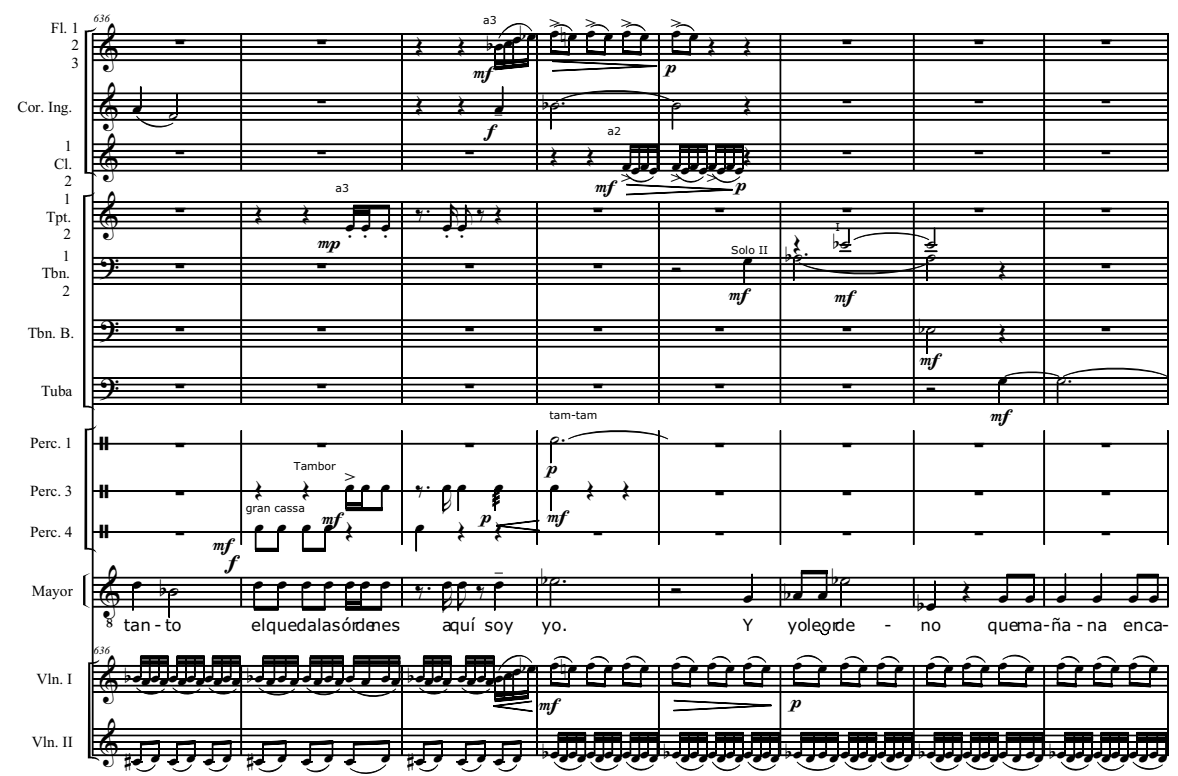

\section{II}
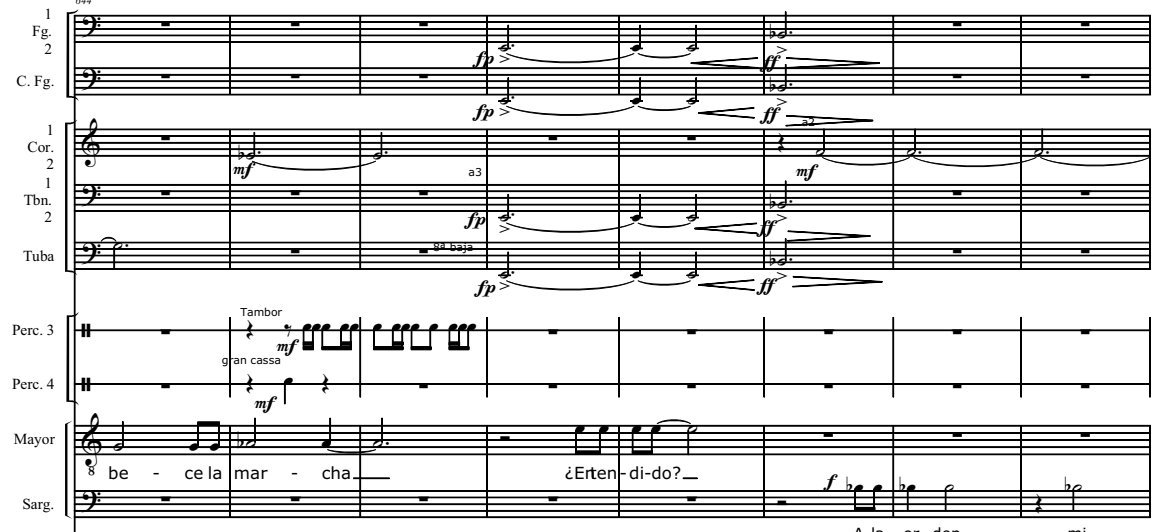

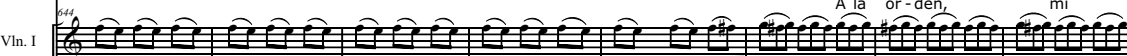
VI.II v.

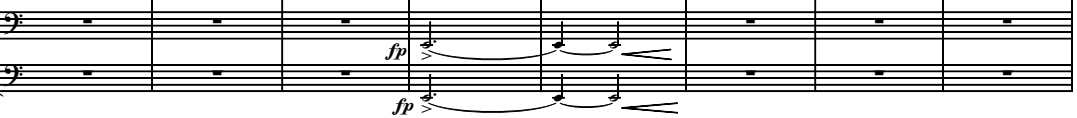



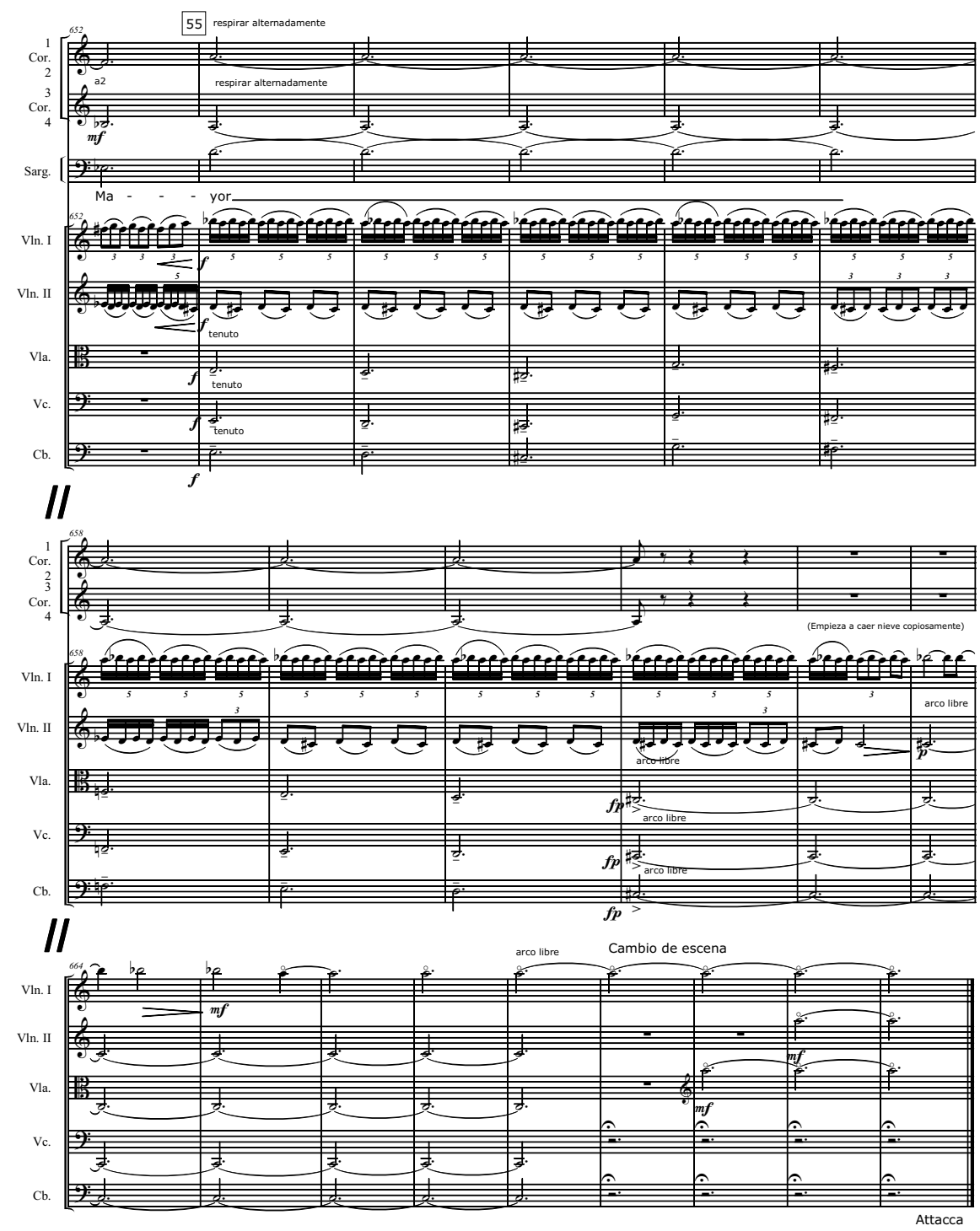
civil o un abogado- que ha estudiado para realizar un trabajo que exige, no sólo tiempo, sino también conocimientos, y no se le pague? ¿Cómo puede ser que habiendo tantas orquestas no tenga cada una un "compositor de la casa" o sea un compositor contratado, por ejemplo, por tres años, para que componga obras que la orquesta incluya en sus programaciones?

SE: Hace varios años que vengo proponiendo a la Fundación de Orquestas Juveniles e Infantiles (y a otras tantas instituciones musicales) la idea del "Compositor en Residencia”. Cómo no va ser posible que la orquesta X invite por unos meses a un compositor para que le escriba una obra a su medida. Sería un gran incentivo para los compositores y de paso solucionaría la falta de material apropiado para el nivel específico en que se encuentra esa orquesta. Por otra parte, daría al movimiento musical una identidad y personalidad propias: jsi tienen a los muchachos tocando, casi exclusivamente, repertorio europeo mal adaptado! Se le hace un pésimo favor a la música, porque se la enseña de manera inadecuada.

Yo aprendí a escribir música haciendo sonar mis trabajos, es ahí donde pude ir descubriendo mi propia voz interior. ¿Qué saco con tener cientos de papeles con notas escritas si jamás han sido tocadas por nadie? La música se materializa como un acto comunicativo en el momento de la ejecución, por eso me parece fundamental restablecer el diálogo entre intérpretes y compositores. Para eso es esencial conocer muy bien a todos los actores que componen el medio musical, incluyendo al público, por supuesto. Siempre me ha llamado la atención la escasísima presencia de colegas compositores en los espacios musicales habituales. Parece que están enclaustrados y salen sólo para los festivales de música contemporánea que organizan una vez por año. Yo me pregunto... ¿Dónde están el resto del tiempo? ¿Por qué no asisten a conciertos de las temporadas de las orquestas estables? Hace falta un poco más de cariño hacia la actividad que hacemos, y preguntarse para qué escribimos música. Aceptar el desafío de escribir obras que puedan ser abordadas por nuestros músicos, en lugar de lamentarse por la falta de oportunidades y quejarse del nivel cultural en que estamos.

Si Chile es reconocido internacionalmente por su buen nivel orquestal y coral, al menos en referencia al resto de Latinoamérica, ¿por qué no nos sumamos los compositores a este movimiento?

SAC: ¿El Fondo de Fomento a la Música Nacional no financia proyectos de este tipo? Y si no lo hace, ¿cuál es la función de dicho Fondo?

SE: El Fondo de Fomento de la Música Nacional sin duda que es un gran avance para la institucionalidad cultural; sin este Fondo tendríamos una actividad mucho más precaria. En el caso de Viento blanco, nos aportó cerca de 6 millones de pesos, que permitieron pagar los honorarios del equipo creativo (compositor, libretistas y diseño integral de la puesta en escena) más el copista. La producción del estreno fue posible gracias a que la Dirección Artística del Teatro Municipal de Santiago se interesó por esta nueva apuesta presentada por un equipo de gente joven (33 años promedio). Sin duda fue la asociación entre el Teatro Municipal y este grupo de creadores independientes lo que permitió llevar esta obra al público. De lo contrario, hubiera sido imposible conseguir el enorme presupuesto 
que significa un montaje que requiere una orquesta de 80 músicos, dos coros, 13 solistas, y el personal técnico necesario para hacerlo bien. Si tuviéramos que contratar en forma independiente cada ítem, llegamos fácilmente al millón de dólares. Es como hacer una película, pero en tiempo real.

Postular al Fondo de la Música se ha transformado para mí en un ejercicio necesario para conseguir aportes a los proyectos que estoy haciendo. Sin embargo, es como jugar a la ruleta, depende del jurado de turno el tener éxito. Muchas veces excelentes proyectos son rechazados por razones poco contundentes. No veo la aplicación de un criterio claro y definido en torno a las políticas culturales que se declaran en la Ley de la Música. Hace falta una mirada amplia y un liderazgo que garantice que los proyectos de excelencia se lleven a cabo. Creo que hay una confusión entre Fondos Artísticos y Fondos Solidarios, lo cual es muy explicable desde el punto de vista sociológico por nuestra profunda influencia católica.

SAC: Con la globalización, el hecho de que Chile está tan aislado y lejos geográficamente ya no es un obstáculo como antes, por ser los editores y la música contemporánea un fenómeno internacional, ¿por qué no contactas a uno de los muchos editores que pertenecen a United Music Publishing u otros europeos o norteamericano, por ejemplo?

SE: Es verdad que el aislamiento geográfico se ha acortado sustancialmente con la globalización. Además, Internet y la edición de partituras en formato digital permite hoy no depender de las editoriales para la impresión del material. Estoy en conversaciones para hacer una editorial que se concentre en la edición de música latinoamericana, para, desde ahí, generar una plataforma que permita sacar nuestras obras al mundo. Es una vergüenza el hecho de que el repertorio nacional no se encuentre disponible para ser tocado ¿No es acaso parte del patrimonio cultural?

SAC: Tú mencionas a los que traban el avance. ¿Cuál es el problema que existe en las estructuras y las personas en torno a la música contemporánea que impide que el arte avance en el buen interés de los compositores chilenos y de la sociedad?

SE: Creo que uno de los temas centrales pasa por la autovaloración de la actividad del compositor. ¿Me creerías si te contara que un grupo de compositores, mientras evaluaban los proyectos de Creación de Música Nacional durante la última convocatoria del Fondo de Fomento de la Música Nacional, argumentaron que "el compositor no debía percibir honorarios por su trabajo"?

¡Es el mejor autogol que se ha visto en la historia de la música en Chile! Los mismos compositores sugiriendo a los señores que administran este Fondo eliminar la única manera existente de financiamiento de la creación de una obra. Si son los mismos compositores y académicos los que proponen que su trabajo no debe pagarse, entonces estamos ciertamente ante un gran problema de valoración de nuestra actividad.

El problema es siempre el mismo: EGO. El EGOísmo y EGOcentrismo tan característicos del artista nacional, nos ha impedido entender y proyectar la dimensión colectiva que tiene nuestro trabajo. Seguir con la actitud sectaria de tribus estéticas que se ignoran o se hacen zancadillas entre sí, me parece un comportamiento 
muy primitivo que no ha contribuido en nada a hacer de este país un lugar donde la música nacional se incluya como un interlocutor permanente en la vida de los ciudadanos.

No hace falta ser siquiatra para entender que detrás de esos rasgos hay una profunda inseguridad. El arribismo cultural produce artistas acomplejados que están más pendientes de quién ganó el último premio en París, antes de preguntarse quién soy y qué puedo hacer yo por mi entorno. En ese sentido, me siento mucho más cerca de los compositores de los años 50 y 60, que fueron verdaderos impulsores de la vida musical del país. Como dijo Sergio Ortega en su última visita a Chile: "Soy un compositor de utilidad pública". 